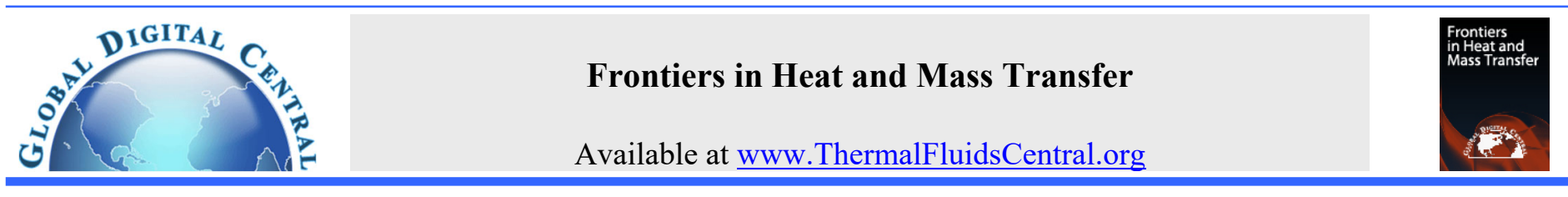

\title{
AN EXPERIMENTAL ANALYSIS OF LIQUID AIR JET PUMP
}

\author{
V. W. Bhatkar a, *, Anirban Sur ${ }^{\text {b, * }}$ \\ ${ }^{a}$ Marathwada Mitra Mandal's College of Engineering, Pune-411052, M.S India \\ ${ }^{b}$ Symbiosis Institute of Technology, Symbiosis International (Deemed University),
} Maharashtra, India

\begin{abstract}
A jet pump or an ejector uses primary fluid flow as motive fluid to entrained secondary fluid. In this paper, the main intention is to find suction flow rate, primary flow rate, secondary flow rate, loss factors and ejector efficiency for an applied pressure. The values of the different loss factors estimated are primary nozzle loss factor $(\mathrm{Kp})=0.06$, suction loss factor $(\mathrm{Ks})=0.04-0.1$, mixing loss factor $(\mathrm{Km})=0.07-0.1$ and diffuser loss factor $(\mathrm{Kd})=0.0289$. It is found that with the increase in pressure across the ejector, efficiency increases with increase in flow ratio and decrease in pressure ratio.
\end{abstract}

Keywords: Ejector, nozzle, primary and secondary fluid, flow ratio; pressure ratio; loss factors

\section{INTRODUCTION}

Heating ventilating air conditioning and refrigeration (HVACR) industries are consuming large quantity of energy that leads to the shortage in energy availability, increase in the energy prices and environmental problems like global warming, carbon emission and pollution. The researchers are working for the renewable energy sources like solar, geothermal and non-conventional methods of refrigeration and air conditioning. The conventional fuel sources are diminishing due to limited supply of natural resources like coal, oil and petrol. This increases the interest among people towards utilizing low grade energy against high grade energy. Ejector refrigeration gives better refrigeration effect using low grade energy or waste heat which is easily available in most of the industrial processes or by using solar radiation and geothermal energy. These systems are becoming popular and attractive among energy conscious people. Ejector system contains no moving parts so it is a vibration free, low running cost and environment friendly system. Ejector refrigeration has relatively low efficiency and complexity in the design of ejector. More research is to be done in the field of ejector refrigeration systems to understand their characteristics, working, performance parameters and to promote their use. Ejector constitutes three main parts such as converging-diverging nozzle, suction nozzle mixing tube and diverging tube. The special names for jet pumps applied to specific services have been introduced by several researchers such as ejector, injector and hydraulic compressor.

Gasoline and O'Brien (1934) developed first water jet ejector explored theoretical analysis and verified it with experimental work. Bonnington et al., (1976) work was used as reference for designing of ejector and the routine trials. Mishra and Paramanik (2019), Sur (2021) studied CFD analysis for isothermal jet for different nozzle distances while mixing pipe length, nozzle diameter and nozzle flow rate are kept constant. Experimental and numerical computations performed by changing diameter, length, protrusion and different nozzle flow rate to compute the air entrainment into the pipe. It was found from the investigation that as the diameter of mixing pipe is increased, the suction rate increases both for isothermal jet and hot jet. Hamad et al. (2019), Solke et al.(2021) found the effect of vapour injection ratio and compressor speed on the compressor power. They observed that the cycle performance was affected strongly by the injected vapour and power supply frequency. They concluded that $2 \%$ of vapour injection is effective for the frequency range from 35 to $40 \mathrm{~Hz}$. As the compressor speed increases, the ratio of vapour injection must be increased to overcome the degree of vapour superheating. Kashyap and Gupta (2011) studied the comparative analysis of ejector refrigeration using R410a and R134a refrigerant in the same ejector geometry at same operating conditions. They found that COP of system increased as boiler temperature increased while $\mathrm{COP}$ is decreased when compression ratio and condenser temperature increased. They found that at ejector ratio of 7.84 at $353 \mathrm{~K}$ has higher COP. For all the area ratio and operating temperatures, the performance of R134a was better than R410a. Aidoun et al. (2019), Gulia et.al. (2021) reviewed mathematical and investigational analysis of ejector in air-conditioning. They researched on various issues in the ejector designs, simulation and different applications. Different shape of nozzle profiles like square, circular, rectangular are studied and among them best one is square edged nozzle profile which gives better air suction effectiveness, easy to manufacture and stable pump operating condition at all flow ratio. Cunningham et al. (1970) researched on ejectors and primary nozzle spacing from the throat. They developed an equation using cavitation index sigma which is used for finding cavitation. Marini et al. (1992) studied the cavitation phenomenon for low area ratio ejectors. Kentfield and Barnes (1972) concluded that diffuser loss coefficient is the important factor in performance enhancement ejector system. Mikhail and Abdou (2005) performed experiment on liquid ejector where primary fluid and suction fluid with different density and viscosity are entrained. Sharif et al. (2019) found out an innovative technique in intercooler as heat exchangers to make use of inlet air in the engine combustion improvement. Turbulent heat transfer distinctiveness was analysed in a convergent-divergent microchannel for Reynolds number varying from 2500 to 7000 . They found that convergent- divergent size microchannel requires additional pumping power to take away the same amount of heat as compared to a rectangular microchannel. Winoto et al. (2000) performed experiments to calculate efficiency of ejectors. They first developed one dimensional governing equation for ideal efficiency. To validate it, they performed the experiments using water jet pump with square and triangular contour

* Corresponding authors. Emails: vijaybhatkar@mmcoe.edu.in (VWB); anirban.sur@sitpune.edu.in (AS) 
like nozzle profile and tested for improvement in the efficiency with flow to the mixing chamber. They showed that experimental results obtained for non-circular nozzle contours decreases the efficiency of ejectors and increase the losses in mixing throat section. The refrigerating capacity of modified ejector cycle was always greater than that of the standard cycle. Sangers (1970) experimented with different throat length, validated theory and gives optimum mixing throat length concept. After several iterations, concluded that for shorter mixing throat length, the mixing extended to diffuser part and for longer throat length loss factors increases. The COP enhancement was higher for nozzle diameter of 1.1 $\mathrm{mm}$, Sumeru et al. (2020). Balamurugan et al. (2006) prepared a semi empirical model to find the rate of entrainment of secondary fluid with the primary fluid. They concluded that throat and nozzle cross sectional areas are important in the design of ejectors. Nian et al. (2019) found that the pressure drop for the tangential jet is more important over normal jet design. Pressure loss coefficients were measured within a leading-edge impingement model with normal and tangential jets were tested for various Reynolds numbers. Boonloi and Jedsadaratanachai (2019) studied the numerical estimates of heat transfer, pressure loss and thermal performance in the heat exchanger square channel equipped with $\mathrm{V}-$ orifice. The variations of orifice height, gap spacing and orifice placement are investigated for the Reynolds number varying from 100 to 2000. The V-orifice in the square channel can create the vortex flow which disturb the thermal boundary layer on the heat transfer surfaces that effects for the augmentation of the heat transfer rate. Bhatkar (2021) considered the mixing length as 10 times of mixing radius to minimize the pressure losses across the ejector.

\section{EJECTOR}

Ejector is used to transfer the momentum of primary fluid flow to the secondary fluid flow during the mixing process. According to the Bernoulli's principle, a low-pressure area is formed through the lowpressure region, secondary fluid is taken into the ejector. The diffusion of the suction fluid in the ejector's throat with the primary fluid stream coming from the nozzle contributes to the two phases being closely mixed. After the mixing in the throat, the diffuser portion helps to relieve pressure. The primary fluid serves two functions; one, it sucks the

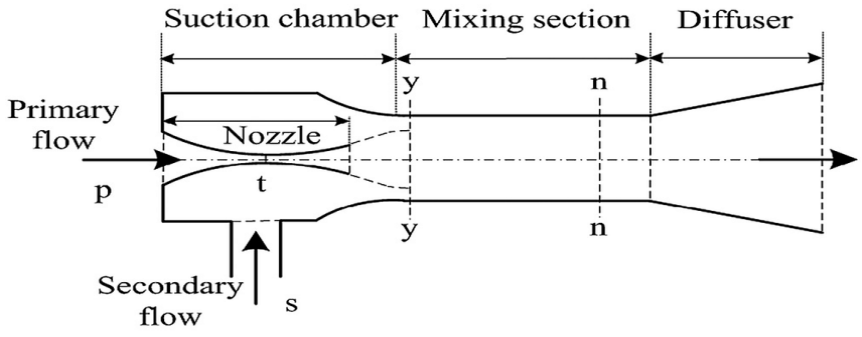

(a) Schematic diagram of ejector

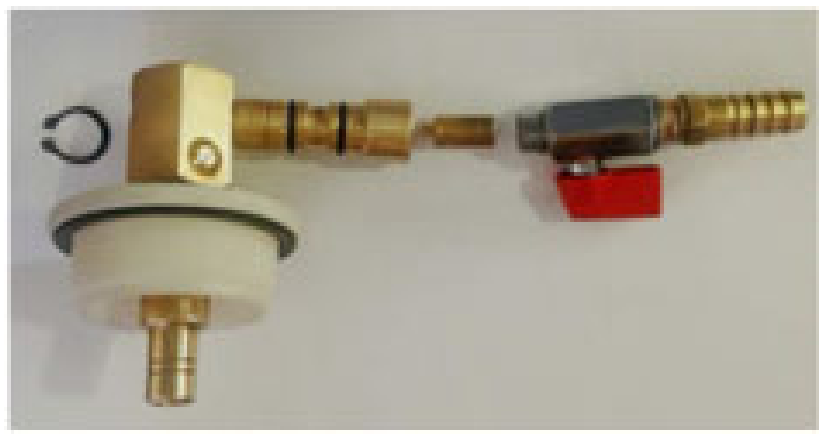

(b) Actual ejector

Fig. 1 Schematic diagram and actual ejector secondary fluid and the other; it provides energy for the conversion of one stage into the other stage. Jet pump contains four parts such as nozzle entrance, suction nozzle, mixing and divergent tube as shown in Fig.1. Table 1 shows the geometrical dimensions of the ejector used in the experimental setup.

Table 1 Geometrical dimensions of ejector

\begin{tabular}{|l|l|l|}
\hline Ejector parameters & Symbol & Value \\
\hline Nozzle diameter & $\mathrm{dn}$ & $9 \mathrm{~mm}$ \\
\hline Nozzle angle & $\Theta$ & $10^{0}$ \\
\hline Throat diameter & $\mathrm{dt}$ & $3 \mathrm{~mm}$ \\
\hline Mixing tube diameter & $\mathrm{D}$ & $9 \mathrm{~mm}$ \\
\hline Length of mixing tube & $\mathrm{L}$ & $30 \mathrm{~mm}$ \\
\hline Diffuser inlet diameter & $\mathrm{di}$ & $9 \mathrm{~mm}$ \\
\hline Diffuser outer diameter & $\mathrm{do}$ & $12 \mathrm{~mm}$ \\
\hline Diffuser length & $\mathrm{Ld}$ & $37 \mathrm{~mm}$ \\
\hline Diffuser angle & $\phi$ & $4^{0}$ \\
\hline Length of suction nozzle & $l$ & $17 \mathrm{~mm}$ \\
\hline Diameter of suction nozzle & $d$ & $10 \mathrm{~mm}$ \\
\hline
\end{tabular}

The increase in kinetic energy across the ejector is largely depending on the loss factors. As the factors are affecting the nozzle performance, all the loss factors such as primary nozzle loss factor $(\mathrm{Kp})$, suction loss factor $(\mathrm{Ks})$, mixing loss factor $(\mathrm{Km})$, and diffuser loss factor $(\mathrm{Kd})$ are experimentally calculated and validated at different pressures with the existing papers, Cunningham (1995). Pressure ratio $(\pi)$ is defined as the ratio of difference between diffuser exit pressure (Pd) and suction pressure $(\mathrm{Ps})$ to the difference between inlet pressure $(\mathrm{Pi})$ to the nozzle and diffuser exit pressure. Ejector performance indicators are the entrainment ratio $(\omega)$ and the compression ratio. The entrainment ratio $(\omega)$ is the ratio of secondary mass flow rate to the primary mass flow rate. The compression ratio $(\tau)$ is the ratio of back pressure to suction pressure.

\subsection{Working}

In the convergent-divergent nozzle, primary fluid enters the convergent part of the nozzle with certain pressure and velocity. In the nozzle, reduction in pressure takes place while in divergent portion fluid velocity increases. From the conservation of energy, pressure decreases as the velocity of fluid increases. Thus, at nozzle exit, low pressure region is developed. In the ejector, due to the difference in pressure between the suction chamber and the secondary flow, entrainment of secondary fluid flow observed. In the mixing chamber at certain length along the ejector, velocity of secondary fluid reached to sonic condition and after that both primary fluid flow and secondary fluid flow mixed with same velocity and pressure. The shocks are formed due to the supersonic in the mixing chamber, momentary compression and drop in velocity from supersonic to subsonic take place. In the diffuser, mixed fluid enters with low

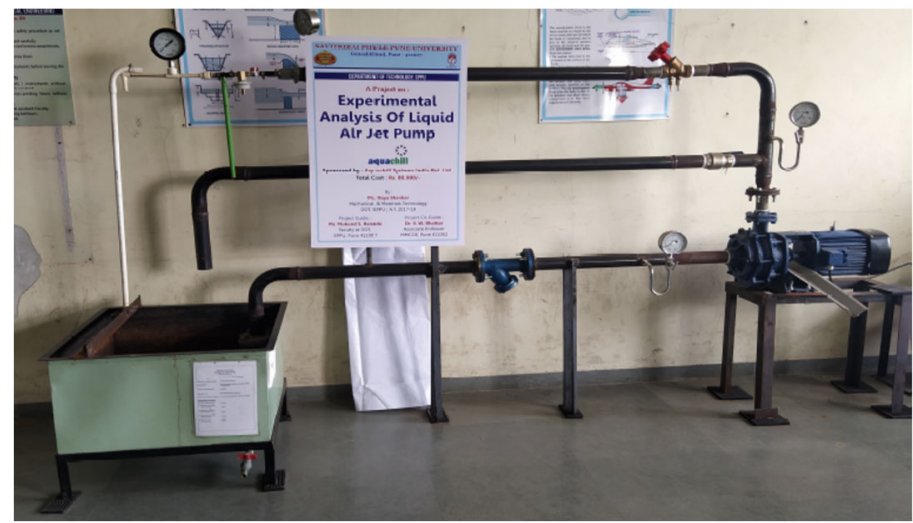

Fig. 2 Experimental setup 
pressure and high velocity. Kinetic energy transformed into pressure energy which leaves from the diffuser with rise in pressure and decrease in velocity. Figure 2 shows the experimental setup used in the research work.

\section{RESULTS AND DISCUSSION}

\subsection{Suction flow rate $(Q s)$}

The suction flow rate is calculated as the product of area of suction tube and velocity through the suction tube of ejector. Figure 3 indicate the suction flow rate with the change in pressure. From the experiment, velocity of air entrained into the suction tube of ejector is found. The velocity is measured by using hand held probe anemometer with \pm 0.1 $\mathrm{m} / \mathrm{s}$ accuracy for the applied pressure. The pressure varies with the change in flow rate by a bypass valve from $0.5 \mathrm{~kg} / \mathrm{cm}^{\wedge} 2$ to $6 \mathrm{~kg} / \mathrm{cm}^{\wedge} 2$. It is found that as the inlet pressure increases, suction of secondary flow rate increases which enhances the performance of ejector.

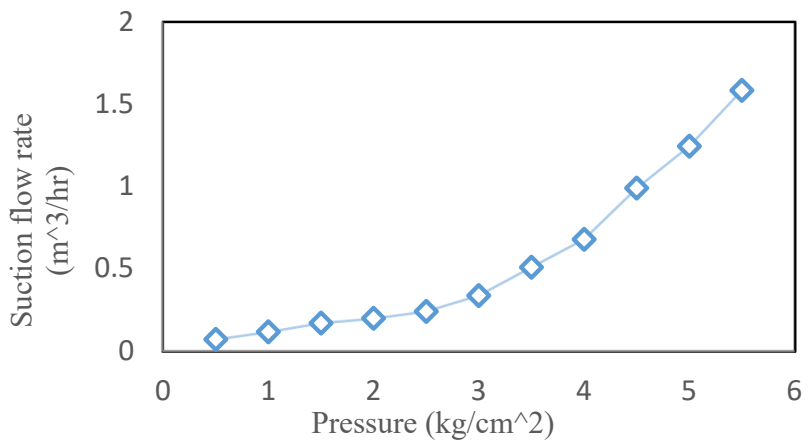

Fig. 3 Variation of suction flow rate with change in pressure

\subsection{Primary flow rate $(\mathrm{Qp})$}

In the experiment, water as a primary fluid is collected in one litre jar and noted the time taken. This step is repeated for every pressure varying from $0.5 \mathrm{~kg} / \mathrm{cm}^{\wedge} 2$ to $6 \mathrm{~kg} / \mathrm{cm}^{\wedge} 2$ to calculate the mean time in second to calculate the primary flow rate. From Fig. 4, it is found that as the pressure increases primary flow rate increases. The primary flow rate is the critical parameter in the performance of the ejector.

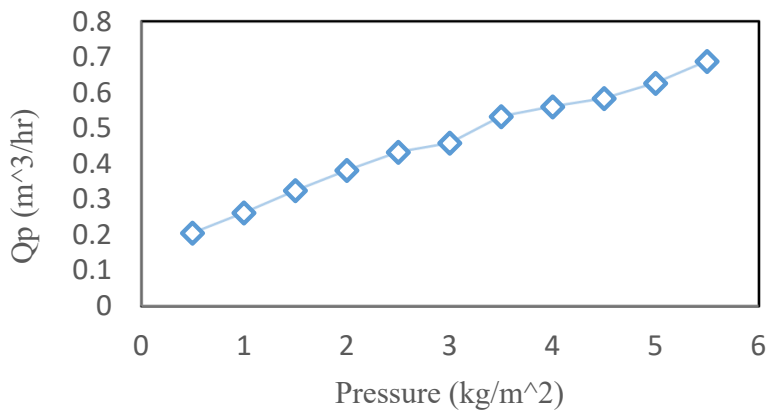

Fig. 4 Variation of primary flow rate with Pressure

\subsection{Flow ratio}

The ejector performance is based on the entrainment ratio or the flow ratio. Two-phase ejector system sucks the air completely into the ejector system and mixed with water. In the mixing process, the primary fluid is losing most of its energy. It is seen that when the flow rate of air is low, flow ratio is higher and when flow rate of primary fluid is higher, the flow ratio is less. From Fig. 5, it is cleared that as the pressure increases, the flow ratio increases with increase in flow rate of air or with suction fluid flow rate.

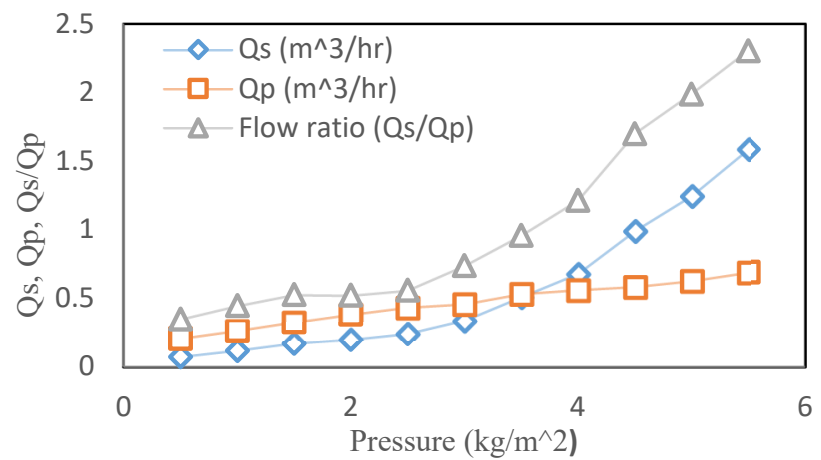

Fig. 5 Primary flow rate $(\mathrm{Qp})$, secondary flow rate $(\mathrm{Q})$ and flow ratio with pressure increase

It is observed that air induced rate is more as compared to primary flow rate (Water) in the ejector system due to different densities that creates turbulence in the mixing chamber. It is found that the suction flow rate is more than primary flow rate in the ejector system.

\subsection{Efficiency of ejector}

Efficiency of ejector is the multiplication of pressure ratio and flow ratio. Figure 6 represents the variation of pressure ratio, flow ratio and efficiency for different pressures ranging from $0.5 \mathrm{~kg} / \mathrm{cm}^{\wedge} 2$ to 5.5 $\mathrm{kg} / \mathrm{cm}^{\wedge} 2$. It is concluded that with the increase in pressure across the ejector, the efficiency increases with increase in flow ratio and decrease in pressure ratio.

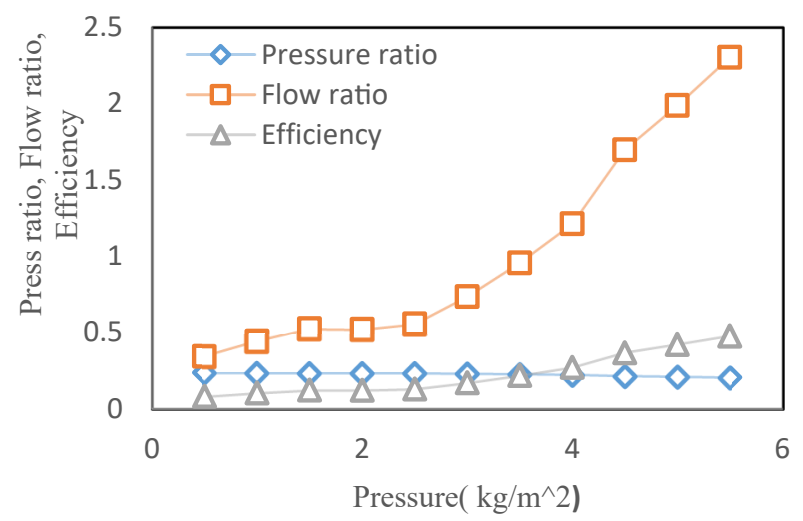

Fig. 6 Variation of pressure ratio, flow ratio and efficiency with applied pressure

\subsection{Loss factors}

The loss factor calculation is important in the design of ejectors. The loss factors are calculated the with the help of geometrical parameters of the ejector for an applied pressure and relations developed in the literature. The loss factors such as primary nozzle loss factor (Kp), suction loss factor $(\mathrm{Ks})$, mixing loss factor $(\mathrm{Km})$, and diffuser loss factor $(\mathrm{Kd})$ are calculated as follows, Cunningham (1995).

$\mathrm{Kp}=0.8 \operatorname{Sin}\left(\frac{\Theta}{2}\right)\left[1-\frac{d n^{2}}{d t^{2}}\right]=0.8 \operatorname{Sin}\left(\frac{10}{2}\right)\left[1-\frac{3^{2}}{9^{2}}\right]=0.06197$

$\mathrm{Ks}=f \frac{l}{d}=0.0279\left(\frac{0.017}{0.01}\right)=0.0474$ 


$$
\begin{aligned}
& \mathrm{Km}=f \frac{L}{D}=0.0249\left(\frac{0.030}{0.009}\right)=0.083 \\
& \mathrm{Kd}=\frac{2.6 \operatorname{Sin}(10 / 2)\left[1-\beta^{\wedge} 2\right]^{\wedge} 2}{\beta}=\frac{2.6 \operatorname{Sin}\left(\frac{10}{2}\right)\left[1-0.75^{2}\right]^{2}}{0.75}=0.0289
\end{aligned}
$$

$$
\text { Where, } \beta=\frac{d i}{d o}=\frac{9}{12}=0.75
$$

The error analysis is conducted for the experimental instruments used and the error between the theoretical value and the experimental values as shown in table 2 .

Table 2 Error analysis

\begin{tabular}{|l|l|l|}
\hline Sr. No. & Parameter & Error \\
\hline 1 & Nozzle diameter, length & $\pm 0.005 \mathrm{~mm}$ \\
\hline 2 & Nozzle angle & \pm 0.5 degrees \\
\hline 3 & Nozzle suction Pressure & $\pm 1 \mathrm{psi}$ \\
\hline 4 & Velocity & $\pm 0.1 \mathrm{~m} / \mathrm{s}$ \\
\hline 5 & Flow rate & $\pm 0.0122 \mathrm{~m}^{\wedge} 3 / \mathrm{s}$ \\
\hline 6 & Mixing loss factor $(K m)$ & $\pm 4.445 \%$ \\
\hline 7 & Primary nozzle loss factor $(K p)$ & $\pm 25.28 \%$ \\
\hline 8 & Suction loss factors $(K s)$ & $\pm 3.1 \%$ \\
\hline
\end{tabular}

\section{CONCLUSIONS}

Depending on the experimental work, following are the conclusions:

- The mixing length is the critical parameter in the ejector performance

- The angle of divergence at the entry must be below 8 degrees to avoid the separation of flow with proper entry length

- The flow ratio continues to vary with change in motive pressure. Higher is the motive pressure of the ejector, more is the flow ratio. Thus, at higher motive pressure, more suction fluid can be entrained compare to primary fluid

- As the difference of motive pressure and suction pressure increases, the flow ratio increases and pressure ratio decreases

- Experimental values of loss factors calculated are primary nozzle loss factor $(\mathrm{Kp})$ 0.061, suction loss factor (Ks) 0.04-0.1, mixing loss factor $(\mathrm{Km})$ 0.07-0.1 and diffuser loss factor $(\mathrm{Kd}) 0.0289$ are within $\pm 10 \%$

\section{ACKNOWLEDGEMENTS}

The author is thankful to Aquachill Systems India Pvt. Ltd. for sponsoring the project. The author is thankful to Dassault Systemes, La Foundation for funding the project titled "Virtual design and simulation of environmentally friendly combined flow evaporative condenser for cold storage plants" with No: 40/2020.

\section{NOMENCLATURE}

$\begin{array}{ll}K d & \text { diffuser loss factor } \\ f & \text { Friction factor } \\ K m & \text { Mixing loss factor } \\ K p & \text { primary nozzle loss facto } \\ K s & \text { suction loss factors } \\ P d & \text { diffuser pressure } \\ P i & \text { pressure at the entry of ejector } \\ P s & \text { secondary pressure } \\ Q p & \text { primary fluid (water) flow rate } \\ Q s & \text { secondary fluid flow rate } \\ \text { Symbols } & \\ \pi & \text { pressure ratio }\end{array}$

$\begin{array}{ll}\phi & \text { flow ratio } \\ \omega & \text { entrainment ratio } \\ \tau & \text { compression ratio } \\ \beta & \text { Diffuser inside to outside diameter ratio }\end{array}$

\section{REFERENCES}

Aidoun Z., Ameur, K., Falsafioon, M., Badache, M., 2019, "Current Advances in Ejector Modeling, Experimentation and Applications for Refrigeration and Heat Pumps Part 1: Single-Phase Ejectors," Inventions 4 (15), 1-73. http://dx.doi.org/10.3390/inventions4010015

Balamurugan, S., Gaikar, V., Patwardhan, A., 2006, "Hydrodynamic Characteristics of Gas Liquid Ejectors," Chemical Engineering Research and Design, 84 (12), 1166-1179. http://dx.doi.org/10.1205/cherd05062

Bhatkar, V.W., 2021, "Thermal Simulation of a Liquid-Air Jet Pump," JP Journal of Heat and Mass Transfer, 23 (2), 225-233. http://dx.doi.org/10.17654/HM023020225

Bonnington, S., King, A., Hemmings, J., 1976 “Jet Pumps and Ejectors: A state of the art review and bibliography," BHRA Fluid Engineering, Cranfield. https://catalogue.nla.gov.au/Record/212903

Boonloi, A., and Jedsadaratanachai, W., 2019, "The Effects of Gap Spacing Ratio on Flow Structure and Heat Transfer Characteristic for The V - Orifice in the Square Channel Heat Exchanger," Frontiers in Heat and Mass Transfer, 12 (19), 13 pages.

http://dx.doi.org/10.5098/hmt.12.19

Cunningham, R.G., 1995, "Liquid Jet Pumps for Two Phase Flows," Journal of Fluids Engineering, 117 (2), 309-316. https://doi.org/10.1115/1.2817147

Cunningham, R., Hansen, A., Na, T., 1970 "Jet Pump Cavitation," Journal of Basic Engineering, 92 (3), 483-492. https://doi.org/10.1115/1.3425040

Gasoline, J.E., O’Brien, M.P., 1934, “The Water Jet Pump,” University of California Publications in Engineering, 3, 167-190.

https://asmedigitalcollection.asme.org/gasturbinespower/articlepdf/91/2/140/5885935/137 2.pdf

Hamad, A., Khalifa, H., Khalaf, D., 2019, "Performance Investigation of Vapor Compression Cycle with A Variable Speed Compressor and Refrigerant Injection," Journal of Mechanical Engineering, 16 (2), 63 76. https://jmeche.uitm.edu.my/wp-content/uploads/2019/08/6\%20P1806\%20Final.pdf

Kentfield, J., Barnes, R., 1972, "The Prediction of the Optimum Performance of Ejectors," Proc. The Institution of Mechanical Engineers, India, 671- 681.

http://dx.doi.org/10.1243/PIME PROC $1972 \quad 186 \quad 083 \quad 02$

Kashyap, S., Gupta, R., 2011, "Theoretical Study of Ejector Refrigeration System with Working Fluid R410a," International Journal of Engineering Science and Technology, 3 (8), 6508-6513.

Marini, M., Massardo, A., Satta A., Geraci, M., 1992, "Low Area Ratio Aircraft Fuel Jet-Pump Performances with and Without Cavitation," Journal of Fluids Engineering, 114 (4), 626-631. https://doi.org/10.1115/1.2910077

Mikhail, S., Abdou, H., 2005, "Two-Phase Flow in Jet Pumps for Different Liquids," Journal of Fluids Engineering, 127 (5), 1038-1042. http://dx.doi.org/10.1115/1.1990203

Mishra, D., Paramanik, S., 2019, "Computation of Air Entrainment into A Mixing Pipe: An Experimental and Numerical Analysis," Journal of Mechanical Engineering, 16 (2), 11-28. 
https://jmeche.uitm.edu.my/wp-content/uploads/2019/08/2\%20P1834\%20Final.pdf

Nian, W., Migjie, Z., Sulaiman, A., Lesley, M., Wright, Je, Chin Han, 2019, "Turbine Blade Leading Edge Impingement Cooling from Normal or Tangential Jets with Crossflow Effect," Frontiers in Heat and Mass Transfer, 13 (9), 13 pages. http://dx.doi.org/10.5098/hmt.13.9

Sanger, N.L.,1970, "An Experimental Investigation of Several Low Area-Ratio Water Jet Pumps," Journal of Basic Engineering, 92 (1), 11-19.

https://doi.org/10.1115/1.3424917

Solke, N., Sur, A.2021 "Material selection and design of shell and tube heat exchanger for thermos-syphon steam generator"

IOP Conf. Ser.: Mater. Sci. Eng. 1104012009 https://doi.org/10.1088/1757-899X/1104/1/012009

Sur, A., Solke, N., Pandiya,S. 2021,'Design and analysis of nozzles for pneumatic windshield wiper" IOP Conf. Ser.: Mater. Sci. Eng. 1104 012002

https://doi.org/10.1088/1757-899X/1104/1/012002
Gulia.V, Sur.A,2021" "Influence of Mass Flow Rate and Concentration of Al 2 O 3 Nanofluid on Thermal Performance of a Double Pipe Heat Exchanger" Advances in Mechanical Processing and Design, 33-45 https://doi.org/10.1007/978-981-15-7779-6 3 3

Sharif P.M., Hairuddin, A., Arry, A., Rezali, K., Noor, M., Sharif, S., 2019, "Development of Evaporative Intercooler Heat Exchanger for Vehicle Charge Air Enhancement Using CFD Simulation," Journal of Mechanical Engineering and Sciences, 13 (4), 6195-6217. https://doi.org/10.15282/jmes.13.4.2019.29.0485

Sumeru K., Firdaus, M., Pratikto, P., Badarudin, A., 2020, "Investigation of Modified Ejector Cycle on Residential Air Conditioner with Environmentally Benign Refrigerant R290," Journal of Thermal Engineering, 6 (6), 297-312. https://doi.org/10.18186/thermal.711539

Winoto, S.H., Li, H., and Shah, D.A., 2000, "Efficiency of Jet Pumps," Journal of Hydraulic Eng. 126, 150-156. http://dx.doi.org/10.1061/(ASCE)0733-9429(2000)126:2(150) 